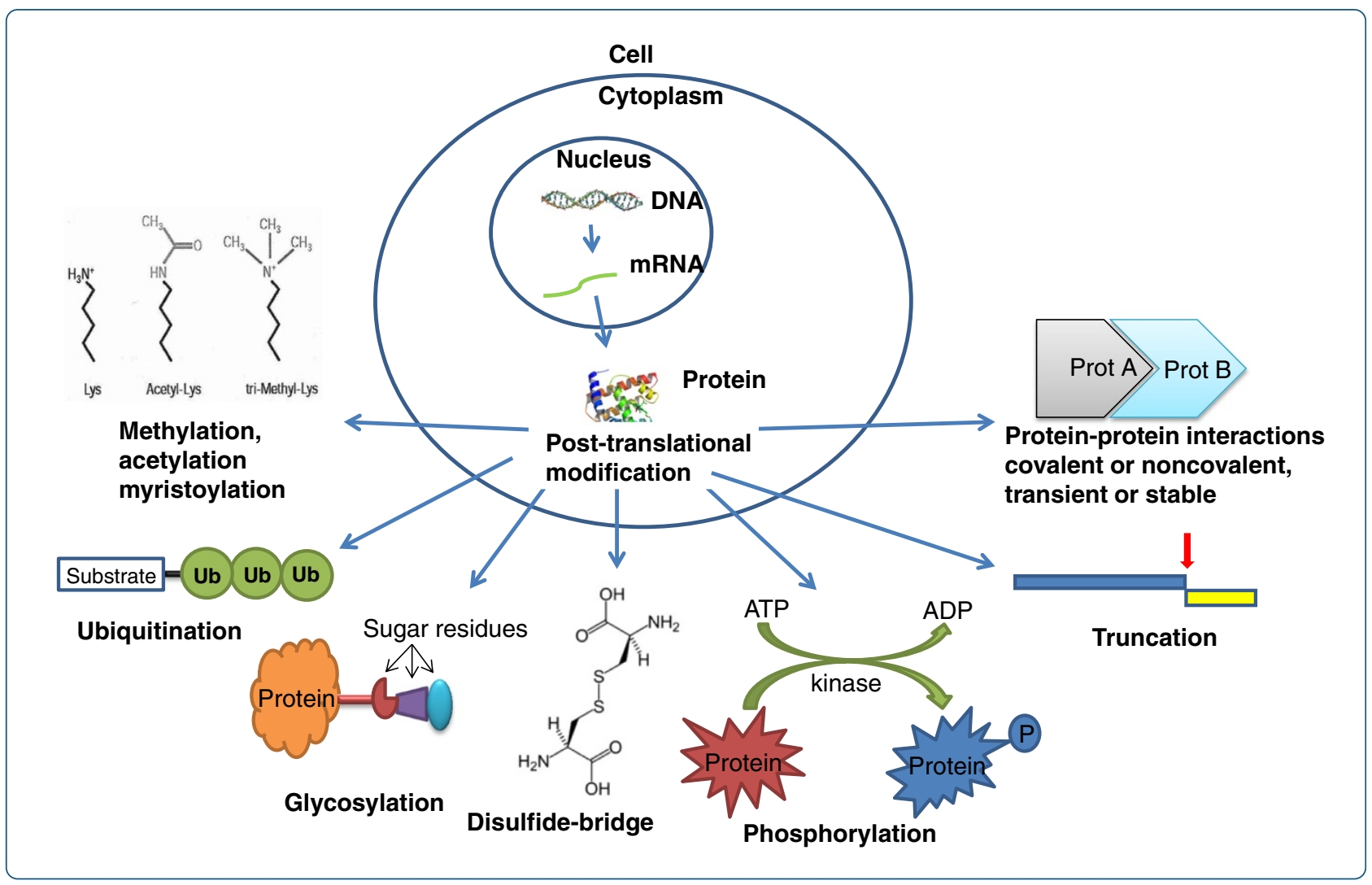

\title{
Mass spectrometry as a tool for studying autism spectrum disorder
}

Woods et al. 


\title{
Mass spectrometry as a tool for studying autism spectrum disorder
}

\author{
Alisa G Woods ${ }^{1 *}$, Armand G Ngounou Wetie ${ }^{1}$, Izabela Sokolowska' ${ }^{1}$, Stefanie Russell², Jeanne P Ryan², \\ Tanja Maria Michel ${ }^{3}$, Johannes Thome $e^{3,4}$ and Costel C Darie ${ }^{1}$
}

\begin{abstract}
Autism spectrum disorders (ASDs) are increasing in incidence but have an incompletely understood etiology. Tools for uncovering clues to the cause of ASDs and means for diagnoses are valuable to the field. Mass Spectrometry (MS) has been a useful method for evaluating differences between individuals with ASDs versus matched controls. Different biological substances can be evaluated using MS, including urine, blood, saliva, and hair. This technique has been used to evaluate relatively unsupported hypotheses based on introduction of exogenous factors, such as opiate and heavy metal excretion theories of ASDs. MS has also been used to support disturbances in serotonin-related molecules, which have been more consistently observed in ASDs. Serotonergic system markers, markers for oxidative stress, cholesterol system disturbances, peptide hypo-phosphorylation and methylation have been measured using MS in ASDs, although further analyses with larger numbers of subjects are needed (as well as consideration of behavioral data). Refinements in MS and data analysis are ongoing, allowing for the possibility that future studies examining body fluids and specimens from ASD subjects could continue to yield novel insights. This review summarizes MS investigations that have been conducted to study ASD to date and provides insight into future promising applications for this technique, with focus on proteomic studies.
\end{abstract}

Keywords: Mass spectrometry, Proteomics, Protein biomarkers, Autism spectrum disorder

\section{Review \\ Introduction}

Mass spectrometry (MS) has been employed as a tool for understanding various biomedical disorders, and is more recently being used to investigate psychiatric disorders, including autism spectrum disorders (ASDs). Although initial MS studies have focused on identifying exogenous factors, more recent investigations are being conducted to understand endogenous protein changes and to identify possible ASD biomarkers. Here we summarize how MS has been employed to understand ASDs, and we provide a perspective on the likely future of investigations of ASDs using this technique.

Autism spectrum disorders (ASDs) are characterized by social deficits, repetitive/stereotypical behaviors and interests, as well as communication problems [1]. These disorders include autism, Asperger's syndrome and pervasive developmental disorder not otherwise specified

\footnotetext{
*Correspondence: awoods@clarkson.edu

'Biochemistry and Proteomics Group Department of Chemistry and Biomolecular Science, Clarkson University, 8 Clarkson Avenue, Potsdam, NY 13699-5810, USA

Full list of author information is available at the end of the article
}

(PDD-NOS) [2]. Most recent available estimates of ASD indicate a prevalence of 1 in 88 US children. ASDs are more frequent in boys than girls, with a relative prevalence of one in 54 boys and one in 252 girls [3]. This indicates a continued increase in ASD incidence, however, the contribution of a true increase versus improvements in awareness and diagnosis is currently unknown [3]. Many researchers believe that improved detection alone does not account for the increased ASD incidence [4].

Current classifications for ASDs may change in the upcoming DSM-V (Diagnostic and Statistical Manual of Mental Disorders, fifth edition), in which autism will no longer be a separate diagnostic category within the larger classification of Pervasive Developmental Disorder, but rather encompassed under the broader ASD category. ASD will also encompass several syndromes that were individually classified in the DSM-IV-TR (DSM, fourth edition, Text Revision); Asperger's disorder and PDDNOS will be eliminated [5]. Reflecting the common characteristics of ASD subtypes, diagnosis of ASD in DSM-V will require both "social/communication deficits" and "fixated interests and repetitive behaviors" to be satisfied [5].

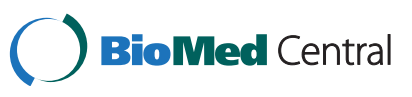


It has been suggested that based on these new criteria, fewer individuals will be diagnosed with ASD [6]. This underscores the need for diagnostic means other than by simply measuring ASD symptoms.

It has been suggested that a small percentage of children diagnosed with ASD will spontaneously completely recover from symptoms, somewhere between 5-32\% depending on the report [7]. However, these assessments are somewhat contradicted by the fact that ASDs are pervasive developmental disorders and therefore the diagnosis cannot be made if the symptoms are transient in nature. The existence of spontenous recovery remains an area of controversy. Behavioral interventions for ASDs, particularly when initiated at as early an age as possible, have been demonstrated to reduce ASD symptoms in $47-48 \%$ of cases [8-10]. Improvements in treatment are therefore still greatly needed. Despite the success of behavioral treatments, they are often initiated late due to delays in diagnosis. Pharmacological treatments of approved medications have not yet been demonstrated to be effective for ASD symptoms [11-13]. Several mGluR5 antagonist candidates as well as GABAergic agonists are currently being investigated for fragile $\mathrm{X}$ syndrome, the most validated and extensively studied genetic cause of ASDs [14]. These compounds may represent the first indicated medications for a known syndrome associated with ASD symptoms. There is no current medication indicated for ASD treatment, although individuals with ASDs are sometimes prescribed medication for various behavioral symptoms. They also may receive psychiatric medication for psychiatric comorbidities, such as depression. ASDs often are accompanied by other psychiatric problems $[15,16]$.

Current theories of ASD etiology point toward a genetic and environmental interaction [17]. A large body of evidence on genetic information in ASDs currently exists [18-21], although this has not made the etiology of the disorder any less equivocal. Based on a twin study, risk for ASD is more than 20-times increased in firstdegree relatives [22]. Other studies have reported from $60 \%$ to $92 \%$ ASD concordance in monozygotic twins and from $0 \%$ to $10 \%$ in dizygotic twins [22,23]. Despite this evidence for a strong genetic component, conclusively associated genes have remained unidentified, with over 100 genes and 40 genomic loci reported as being associated with ASD $[24,25]$. A recent study of de novo mutations in ASD indicates that many mutations found in individuals with ASDs are in fact unassociated with the disorder [26]. This evidence points toward possible heterogeneity of ASD genetic causality [27] and also indicates that genetic information may not be sufficient to understand ASD etiology. Multiple genes in conjunction with environmental factors may interact to cause ASD [27-29]. The complexity of ASD makes genetic testing for ASDs relatively unsuccessful in many instances [28]. Although numerous studies have pointed to various biological disturbances present in children with ASDs [30-33], no current biological marker is available to aid in ASD diagnosis. ASDs are diagnosed based on behavioral symptoms, including language delays. ASDs therefore often go unrecognized until a child is at least 2 years old or even older, and current screening instruments for ASDs generate many false positives [34].

In this regard, we advocate the use of the mass spectrometer as a possible screening instrument for ASDs for many reasons. High-performing mass spectrometers, simplified analytical workflows and versatile data analysis tools render the technique easy, fast, accurate, reproducible and reliable compared to genetic studies. Further, dynamics at the environmental, developmental and genetic stages are truly reflected at the protein level. Moreover, proteomics could lead to the discovery of proteome fingerprints or profiles specific to ASD and therefore to biomarker discovery for the diagnosis, prognosis, monitoring and target identification for treatments for this disorder (Figure 1).

\section{Mass spectrometry and proteomic analysis in autism spectrum disorders}

Proteomics has the power to complement genetic information by identifying subtypes of ASD, or by identifying common protein dysregulations caused by different genes [35]. Proteomics is the study of the total complement of proteins at the time of harvest in a specific cell, organelle, extracellular fluid or tissue [36]. Proteomics can convey information that goes beyond genomic analysis, such as indications of active protein levels [37] or possible important post-translational modifications such as glycosylation, phosphorylation, and formation/destruction of disulfide bridges that maintain or disturb the protein's three-dimensionality [35], summarized in Figure 2. The mass spectrometer is the workhorse of proteomic analyses but it can also be used to identify other relevant compounds [38] potentially associated with ASDs, such as environmental or ingested toxins or metabolites [39].

Several different bodily fluids or products can be analyzed by MS: urine, blood sera, saliva, hair and tissue biopsies (Figure 3). Proteomic analysis of brain tissue, including synaptic proteins, using MS is also possible, although this approach tends to be limited to ASD animal models $[40,41]$. There are different reasons why a specific bodily fluid or specimen is chosen for a particular proteomic experiment. Blood serum contains proteins, nucleic acids, lipids, and other metabolic products due to the nature of blood as a complex liquid tissue. This makes blood serum a rich source of disease biomarkers [42]. In contrast to blood, urine can be obtained noninvasively and in large proportions. Urinary proteins 


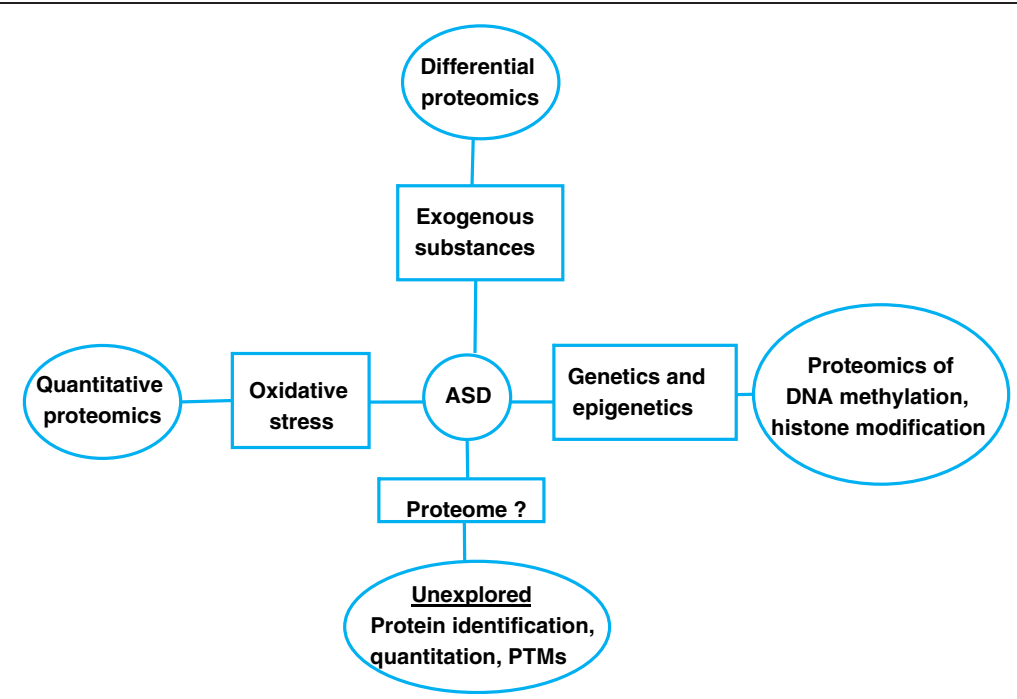

Figure 1 Current proteomic approaches for MS investigations in ASD. Several studies have suggested the causality of ASD to be of genetic and/or epigenetic origin as well as to involve exogenous toxicants (metals, environmental contaminants. MS studies have therefore initially focused on identification of exogenous substances. The proteome, which constitutes the most dynamic entity in human physiology, has not been as extensively studied. Mass spectrometry can also be used for the analysis of the proteome of ASD samples. This includes modifications of DNA, such as methylation or histone modification, qualitative proteomics, which identify protein patterns in controls versus ASD without necessarily implicating specific proteins and ASD proteome identification. This last area of study may be particularly promising for shedding light on ASD etiology or providing potential diagnostic biomarkers.

consist mainly of plasma proteins and proteins secreted from the kidney and urinary tract. The lower complexity of the urinary proteome compared to the serum proteome makes detection of low-abundant molecules much easier. Saliva is comparable to urine with the added benefit that it contains less salt than urine. Salts are not desired in MS experiments [43].
MS analysis of proteins or peptides mixtures allows the identification of proteins by measuring the mass-tocharge ratio of gas phase ions. A mass spectrometer is made of three main parts: an ion source, an analyzer, and a detector. The ion source is the part of the mass spectrometer where molecules are converted into gas phase ions which are then separated in the analyzer and

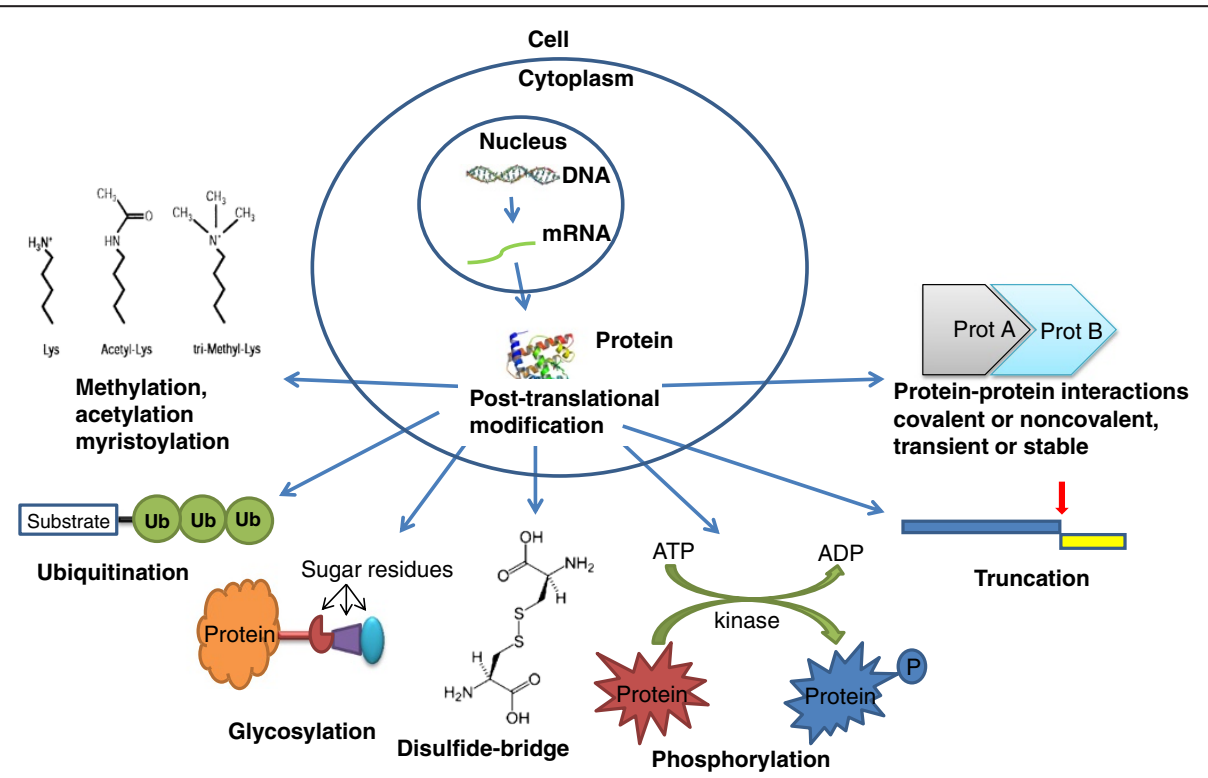

Figure 2 Most common protein PTMs possibly relevant in ASD. Despite the numerous susceptibility genes advanced for ASD, none of these genes has been confirmed to date. Perhaps, genetic disturbances in ASD manifest themselves first on the protein level as aberrant modifications of a protein or a set of proteins (e.g. truncation, phosphorylation, glycosylation, disulfide-bridge or protein-protein interaction). 


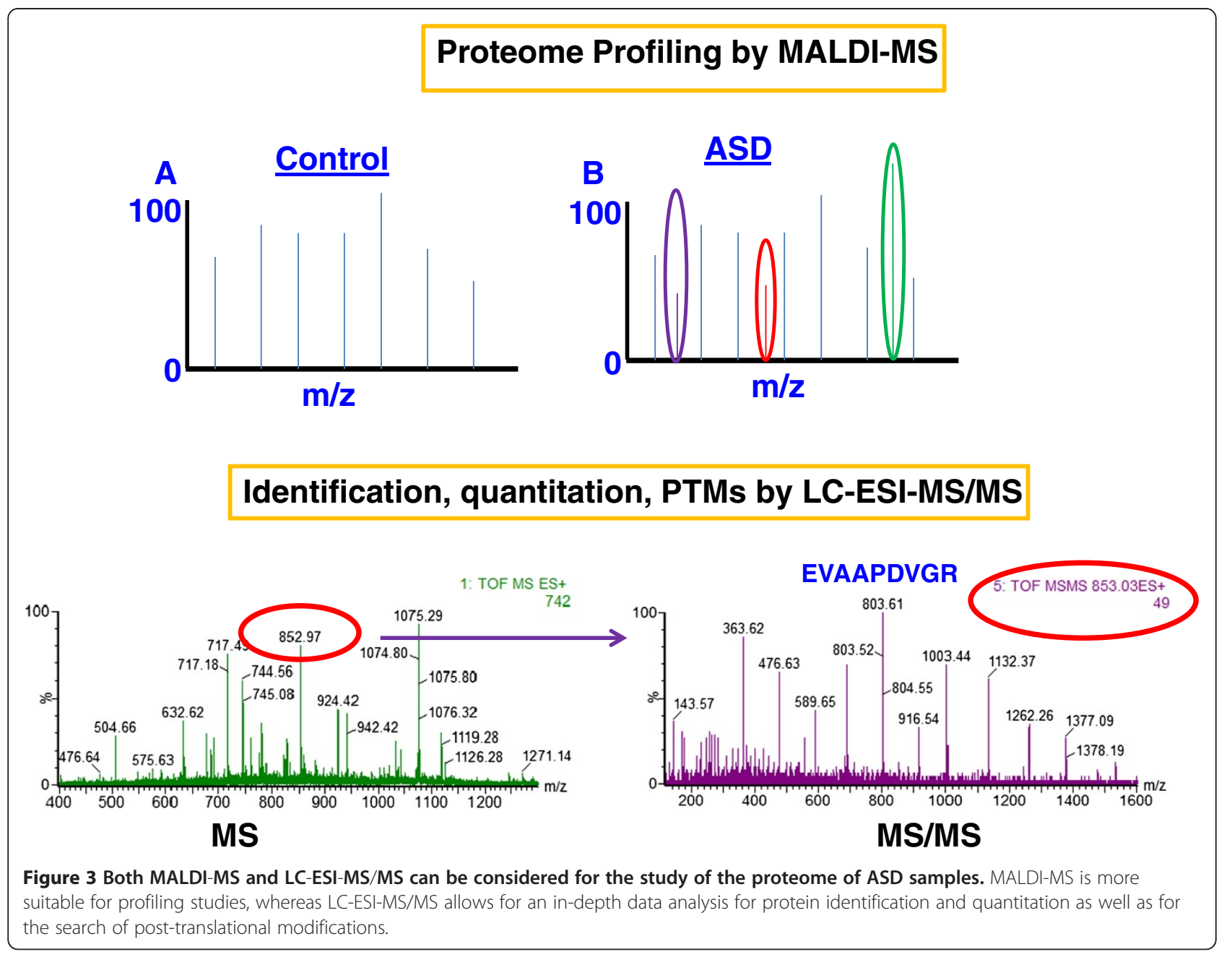

the signal is generated by the detector. The most common ion sources are MALDI (Matrix-Assisted Laser Desorption/Ionization) and ESI (ElectroSpray Ionization). Ionization in a MALDI source occurs through a pulsed laser beam that sublimates molecules whereas in ESI, ionization takes place by subjecting liquid droplets to high voltage at atmospheric pressure [44]. There are several mass analyzers: TOF (Time-Of-Flight), quadrupole, ion trap, and FT-ICR (Fourier Transform Ion Cyclotron Resonance) [45]. There are variants of MS, in which the intact proteins are analyzed (top-down proteomics), or the protein molecules are first digested (e.g. by Trypsin) and the resulting peptides are then analyzed by MS (bottom-up proteomics) [36,46-60]. Of the two approaches, bottom-up proteomics is the most established because of some of the limitations of the top-down approach; it is restricted to simple protein mixtures, instruments are very expensive and there are difficulties in analyzing high molecular weight proteins, the presence of post-translational modifications within the proteins, as well as the presence of both intact and truncated proteins within the same sample [61].
When the peptides generated in bottom-up approaches are first separated by liquid chromatography (LC) prior to MS, this approach is termed shotgun proteomics. The signal obtained from an MS experiment is given in the form of spectra, which are then compared to a database for protein identification. We will review and summarize the results obtained with different analyses of biological materials for the understanding of changes that occur in ASD versus controls.

\section{Urinary analysis in ASDs}

Of the human biomaterials, urine has been most frequently studied in ASD research. For example, Cass et al., (2008) used high pressure liquid chromatography (HPLC) and Matrix-Assisted Laser Desorption/Ionization-TimeOf-Flight Mass Spectrometry (MALDI-TOF MS) to analyze the urine of 65 boys with autism, compared to the urine of 158 male controls of approximately the same age. MALDI-TOF MS is the best MS method for determining peptide or protein mass and for identifying a protein from a peptide mixture [62]. The purpose of this study was to 
test the hypothesis that exogenously-derived opioid peptides are found in the urine of children with autism, which has been one prevalent view of autism causality, albeit with little empirical support [63]. Indeed, using MALDITOF MS and HPLC, these investigators found no significant differences between the urinary profiles of children with autism versus controls, including an absence of differences in urinary opioid peptides [64]. In another study by Hunter et al., (2003), the same hypothesis was tested using LC-UV-MS (Liquid Chromatography-Ultraviolet-MS) and again the authors could not confirm previous findings that autism results from an opioid peptide excess [65].

A separate study examining the possible presence of opioids in subjects with ASDs used a highly sensitive Liquid Chromotography-ElectroSpray Ionization-tandem Mass Spectrometry (termed LC-ESI-MS/MS or LC-MS/MS for short). This approach allows a researcher to not only identify a protein, but also to determine the protein sequence [62]. MS/MS mode refers to a process by which the mass spectrometer records the peptides' spectra (MS mode) and then peaks are selected according to predefined criteria (e.g. charge state, intensity) for fragmentation via collision-induced dissociation (CID) to produce product ions (MS/MS mode). Thus, this mode makes it also possible to select target peaks or peaks of interest for sequencing or quantitation (single reaction monitoring, SRM) [62]. The researchers developed this method to be selective for opioid peptides in the urine of 54 children with ASD versus 15 age-matched controls using a method called solid-phase extraction (SPE). The targeted peptides included gliadinomorphin, beta-casomorphin, deltorphin 1, and deltorphin 2. These investigators also found no evidence for the presence of excessive opioid peptides in the urine of children with ASDs relative to controls [4]. Based on these results and the previously mentioned studies, continued investigation of the opioid hypothesis does not seem to be warranted and clinical recommendations based on the opioid hypothesis would appear to be unfounded in scientific evidence.

Inductively Coupled Plasma-Mass Spectrometry (ICPMS) was used to test a different relatively unsupported theory of autism - that children with autism excrete an excess of heavy metals $[66,67]$ and that metal chelators can serve as a treatment for autism. ICP-MS is appropriate for analyzing the elemental composition of materials and is therefore good for analyzing metals [68]. Unfortunately, this study tested few subjects; 15 children with autism and 4 controls completed the study. Arsenic, cadmium, lead and mercury urine content was tested during a "provoked excretion" versus baseline. Only three children excreted more metal than baseline during the provoked excretion; two near the level of detection. A third child excreted mercury, but this was corrected based on a dietary change. Overall, this study did not support a heavy metal toxicity theory of autism [69]. This is in contrast to a study examining the heavy metal content of hair. Kern and colleagues examined the presence of sulfhydryl-reactive metals (mercury, lead, arsenic, and cadmium) in the hair of 45 children with autism (1-6 yrs of age) versus 45 gender-, age-, and race-matched typical children. Arsenic, cadmium, and lead were significantly lower in the hair of children with autism as compared to matched controls. Mercury was also lower in the hair of children with autism, but not significantly [39]. The authors concluded that their results could indicate that children with autism have more difficulty in excreting toxic metals versus matched typical children [39]. The detection of heavy metals being low in the hair of children with ASD is an interesting finding however, this theory does not seem to be consistently supported by other studies examining the same heavy-metal excretion theory.

In addition to the measurement of exogenouslyintroduced factors, urinary analysis of endogenous factors, such as metabolites, is possible using MS. A study utilizing LC-MS/MS to analyze the urine of young adults with severe ASD and schizophrenia versus healthy controls ( $\mathrm{n}=15,18$ and 18 , respectively) found that butofenine, a molecule related to serotonin (a neurotransmitter that may be dysregulated in ASD) [70], was elevated in individuals with ASD and schizophrenia. Butofenine derives from the double-methylation of serotonin and may have hallucinogenic properties [71,72]. Butofenine also correlated with scores of hyperactivity in these individuals [70]. Although the subject numbers were not high in this study, the results are consistent with a pattern of serotonin abnormalities that have been observed in numerous ASD studies [63]. Abnormalities in the serotonergic system were also observed in a study of 33 children with autism versus 21 healthy children, which used gas chromatography-mass spectrometry (GC-MS) to examine urinary levels of tryptophan (an amino acid responsible for bodily serotonin production). This form of MS is commonly used for metabolites in blood and urine, among other applications [73]. Urinary tryptophan was significantly lower in children with autism than healthy controls, including those on a restricted gluten- and casein-free diet [74]. An early study using HPLC and mass spectrometry found that increases in a serotonin-uptake peptide were also observed in the urine of $67 \%$ of children diagnosed with autism ( $\mathrm{n}=135$ ) using DSM-III-R (DSM, third edition, Revised) criteria when compared to healthy controls $(n=126)$ [75].

MS evidence supports an oxidative stress theory of autism, another current prevalent theory [17]. Oxidative stress refers to the generation of reactive oxygen species which can cause cellular and tissue damage [62]. GCMS was used to measure urinary levels of markers for lipid peroxidation (isoprostane $\mathrm{F}$ (2alpha)-VI), platelet activation (2,3-dinor-thromboxane $\mathrm{B}(2)$ ) and endothelium 
activation (6-keto-prostaglandin $\mathrm{F}$ (1alpha) in children with autism $(\mathrm{n}=26)$ versus healthy control subjects ( $\mathrm{n}=12)$. Subjects with autism had higher urinary markers for lipid peroxidation and endothelium activation. Levels of lipid peroxidation correlated with levels of platelet and endothelium activation [76]. MS is an effective means for measuring oxidative stress markers [62] and further mass spectrometric studies of ASD samples can help to clarify the role that oxidative stress may play in ASD.

Taken together, these MS analyses have supported that oxidative stress and dysregulation of serotonin and related molecules may be present in ASD. These studies did not however, strongly support theories involving the introduction of exogenous substances such as heavy metals and diet-derived opioids as causal factors in ASDs. Based on these MS findings and additional studies, the field has moved forward in the study of endogenous molecules in ASD using MS, and specifically proteomics.

\section{Blood sera analysis in ASDs}

Blood serum is one of the most common bodily fluids that have been studied in ASD, primarily for examining endogenous changes. This is not always a feasible method, due to the invasive nature of a blood draw and the possible reluctance of children and their parents to allow this. Taurines et al., (2010) found protein differences in 16 subjects with ASD and ADHD ( $\mathrm{n}=9$, without ADHD $\mathrm{n}=7 ; \mathrm{ADHD}=$ attention deficit hyperactivity disorder) versus 16 age-matched controls. They reported three peaks with differences, however did not aim to definitively identify the actual proteins [77]. They have suspected that the protein may be an apolipoprotein [38]. Corbett et al., (2007) found elevations in apolipoprotein (apo) B-100 and apo AIV in children with high functioning versus low-functioning autism. These researchers also observed alterations (upregulation) in complement factor $\mathrm{H}$-related protein, complement $\mathrm{C} 1 \mathrm{q}$ and fibronectin 1 and apoB-100 in children with autism versus matched controls [78]. These results showing changes in apolipoproteins (responsible for cholesterol metabolism and transport) are consistent with current theories proposing that disturbances in the cholesterol system may underlie some forms of ASD [33,79,80].

Promising mass spectrometric analyses using RP-LCESI-TOF-MS or MALDI-TOF-MS (common types of MS instruments) [77,78] of blood in subjects with ASD have begun to emerge from the Childhood Autism Risk from Genetics and the Environment (CHARGE) Study being conducted at the University of California, Davis, a large study addressing numerous susceptibility factors for autism, and their interactions [81]. For example, blood mercury levels were found to be unaltered relative to controls in children 2-5 years old with autism or ASD (with developmental delay) relative to controls [82]
( $\mathrm{n}=249, \mathrm{n}=60, \mathrm{n}=143$, respectively). Possible presence of polybrominated diphenyl ethers (PBDEs) in children with autism and developmental delay were also assessed in 100 subjects from this study using GC-MS. No differences were observed in the plasma levels of PBDEs in children with autism or ASDs/developmental delay in this study [83]. This report again emphasizes the utility of MS methods for assessing the presence of possible environmental toxins in individuals with ASDs. It also underscores the need to assess subjects from different populations and geographical regions in order to examine the possible influence of environmental contaminants in the etiology of ASDs. Russo and Devito [84] found increased plasma levels of copper during analysis of plasma from 79 individuals with autism, 52 individuals with PDD-NOS, 21 individuals with Asperger's Syndrome using ICP-MS. Further, they investigated zinc plasma levels and found in this case no significant alterations in zinc concentrations in individuals with autism, PPD-NOS and Asperger's Syndrome. Zinc and B-6 therapy resulted in a decrease in copper concentration in autism and PPD-NOS patients but not in patients with Asperger's Syndrome whereas the zinc levels were higher in all of the three conditions [84].

An addition application for MALDI-TOF in the study of ASD lies in the analysis of genomic modification, such as DNA methylation. For example, MALDI-TOF-MS has been shown to be more suitable for high-throughput methylation analysis in blood testing of individuals for the fragile $\mathrm{X}$ syndrome than the current gold-standard for molecular diagnosis of this disorder, Southern blotting. One study showed that differential methylation of two fragile X-related epigenetic elements within the fragile $\mathrm{X}$ mental retardation gene intron 1 (FMR1) was related to depletion of fragile $\mathrm{X}$ mental retardation gene product (FMRP) expression [85]. An additional study examining FMR1 intron 1 methylation used MALDITOF MS to analyze the blood of 74 controls compared with 62 premutation (between 55-200 CGG repeats in the FMR1 gene) or 18 full mutation (more than 200 CGG repeats) females. These investigators found that FMR1 intron 1 hyper-methylation was predictive of verbal cognitive impairment assessed using Wechsler intelligence quotient tests [86]. This is an example of how MS can be used to measure a biochemical parameter that is predictive of behavior. As other ASD biomarkers are revealed, these may also be correlated with behavior and used to predict ASD severity. Such information could in turn be used to guide types of treatments and when to initiate treatment.

\section{Salivary analysis in ASDs}

Saliva has been assessed using mass spectrometry and saliva components match the contents of blood in many 
instances [87-89]. This is also a less invasive method for examining protein differences in individuals with ASDs. Saliva may provide an accessible biomaterial identifying biomarkers, for example, elevated phosphorylated tau has been measured in the saliva of subjects with Alzheimer's disease relative to controls [90] and salivary uric acid has been used as a biomarker for metabolic syndrome [91]. However, only one published study examining saliva components in ASDs is currently available. Castagnola and colleagues (2006) used one type of MS (HPLC-ESI-Ion Trap-MS or High Performance Liquid ChromatographyElectroSpray Ionization- Ion Trap- Mass Spectrometry) to measure salivary peptides in individuals with ASDs (12 with an autism diagnosis, 1 with Asperger's Syndrome, 14 with PDD-NOS) versus age-matched controls. Phosphorylation levels of statherin, histatin 1 and acidic proline-rich proteins (entire and truncated isoforms) were significantly lower in subjects with ASDs. Lower phosphorylation levels of at least one peptide was found in $66 \%$ of all ASD subjects [92].

\section{Limitations of MS}

MS is a versatile tool that one can use in investigation of bodily fluids such as sera, saliva or urine (and many other fluids). However, when MS is used to investigate these fluids, several factors have to be kept in mind, such as sample preparation, sample investigation, data analysis and data interpretation. Each of these steps in which the sample is being processed also has some limitations and one should be aware of them. Perhaps one of the greatest features of a MS-based experiment is both an advantage and a limitation One MS experiment can produce an enormous amount of information/data, however, limitations of MS experiments lie within the data analysis. Although one can obtain a high amount of data, there is a challenge is in interpreting the results. In the most successful MS experiments we do not know or understand the meaning of about 30\% of the spectra. Therefore, no matter how many weaknesses one MS instrument has (e.g. dynamic range, resolution, etc.), the bottleneck and limitation of a MS experiment is restricted to data interpretation, or bioinformatics. Due to the large amounts of data and need for interpretation, one may focus on one set of proteins selecting a set with both biological and clinical relevance. Therefore, the limitations of the MS-based experiments are not MS instrumentbased, but rather bioinformatics-based limitations.

\section{Conclusions}

Proteomics and investigation of possible ASD gene products is one clear application for MS in ASDs. The proteomic researcher using MS needs to consider however, refinements of MS techniques for protein analysis. Simply measuring proteins levels and looking for changes are not sufficient, interpretation of data is also important, if not the key. A proteomics experiment using MS involves several steps, and these steps are continuing to be refined by researchers. Specifically: 1) sample fractionation, enzymatic digestion of proteins into peptides, 3) analysis, 4) database search and interpretation, and 5) data validation, typically using Western blotting (WB) [36]. For example, our recent study found that peptides containing a cysteine residue will be identified as alkylated, but also other peptides. The akylation of non-cysteine-containing peptides was not previously possible to consider in a proteomic database search. This emphasizes that database searching also is in need of refinement in order to improve MS analysis. Therefore, we proposed that during a protein search the researcher should have the option of searching for any alkylated peptide at the N-terminal amino acid [59].

In addition to continued refinements of MS techniques, proteomic studies using MS tend to focus on identification of novel proteins $[57,60,93,94]$ or on increases and decreases in proteins $[54,58]$, but there are other aspects of protein modifications that can be studied. For example, structural characterization, post-translational modifications or alterations in both stable and transient proteinprotein interactions may all be a subject of study [33,36,46-48,55-57,59,62,93-97]. These changes can modify protein function and are important to consider. For example, have recently described the combination of Blue Native PAGE (BN-PAGE) or Colorless Native PAGE (CN-PAGE) with MS as a powerful means for measuring protein-protein interactions [36,48,49,52,95,97]. Additional refinements in proteomic analysis using mass spectrometry continue to be developed [48,53-57,93,94,96,97] and will undoubtably increase the already formidable power of this technique. Proteomic analysis can also be accomplished at several levels, including supracellular, subcellular, intracellular, extracellular, peptides, proteins or protein complexes. Proteomic analysis can focus on classical structural or functional analysis and also on a specific aspect of the proteome, such as protein oxidation, phosphoproteomics, protein methylation or protein secretion $[53,62,85,86,92,98]$.

\section{Future directions}

Several putative markers for ASDs have been identified using mass spectrometry applied to various human biomaterials. Such markers include serotonergic markers, indications of oxidative stress, hypophosphorylation, hypermethylation (in the case of Fragile $\mathrm{X}$ ) as well as apolipoprotein and complement protein dysregulation. Future studies may concentrate on additional post-translational modifications, such as protein nitrosylation, carbonylation, eliminylation. These are modifications that occur in human conditions and because they denature a protein's function most of the time irreversibly they may be of interest for study in ASD. 
The numerous different markers found in ASD samples may be reflective of multiple elements that are disturbed in ASDs and may also reflect ASD heterogeneity. This heterogeneity is also mirrored in the more than 100 genes and 40 genomic loci brought in association with ASD. This implicates that large pools of samples are needed in order to produce results with statistical power. Current theories propose that ASDs have multiple subtypes and etiologies. Future proteomic studies, including those utilizing mass spectrometry, may therefore reveal a biomarker signature unique to each subtype. Biomarker signatures may in turn aid in subtyping ASDs or in determining that different gene mutations may result in common protein perturbations. Correlation of mass spectrometric protein evidence with behavioral measures could additionally aid in defining protein biomarkers as predictive indicators of ASD behavioral symptoms, indeed at least one study has confirmed this possibility [86]. Refinements of protein analytical techniques, such as the development of more sensitive instruments with the ability to detect more proteins, complemented with advanced bioinformatics software for data interpretation will undoubtably advance the field. The availability of new technology will make the re-analysis of biological products in subjects with ASD versus matched controls possible and worthwhile and with the potential to yield additional novel results.

\begin{abstract}
Abbreviations
ASD: Autism spectrum disorders; PDD-NOS: Pervasive Developmental Disorder Not Otherwise Specified; DSM-V: Diagnostic and Statistical Manual of Mental Disorders, fifth edition; DSM-IV-TR: DSM, fourth edition, Text Revision; CHARGE Study: Childhood Autism Risk from Genetics and the Environment Study; PBDEs: Possible Presence of Polybrominated Diphenyl Ethers; FMR1: Fragile X Mental Retardation Gene Intron 1; FMRP: Fragile X Mental Retardation Gene Product; MS: Mass Spectrometry; MALDI: Matrix-Assisted Laser Desorption/lonization; ESI: ElectroSpray Ionization; TOF: Time-Of-Flight; FT-ICR: Fourier Transform Ion Cyclotron Resonance; LC: liquid chromatography; LC-UV-MS: Liquid Chromatography-Ultraviolet-MS; LC-ESI-MS/MS or LC-MS/MS: Liquid Chromotography-ElectroSpray lonizationtandem MS; SRM: Single Reaction Monitoring; SPE: Solid-Phase Extraction; ICP-MS: Inductively Coupled Plasma-Mass Spectrometry; WB: Western blotting.
\end{abstract}

\section{Competing interest}

The authors declare that they have no competing and/or financial interests.

\section{Authors' contributions}

AGW drafted the initial manuscript. All authors contributed to the conceptualisation and interpretation of results and revision of the manuscript, and all authors reviewed and approved the final manuscript.

\section{Acknowledgements}

The authors would like to thank Laura Mulderig, Todd Boyer, Scott Nichols, Nathan Vanderlan, Tim Mascal, Keith Compson, Michael Balloch, Catalin Doneanu, David Chamberlin, Cathy Bolland, Joanne Boland, Janet Gallager, Sean McCarthy, Cristian Cojocariu \& Charles Pragnell from Waters Corporation for the collaborative discount that allowed us to purchase a Micromass Quadrupole Time of Flight (QTOF) Micro mass spectrometer. The authors also thank Drs. Vlad Artenie and Kenneth R. Woods for advice and support. Thanks to Mary Stewart Joyce, Kenneth Sandler, University of Rostock, the Alexander von Humboldt Foundation and SciFund Challenge for supporting our work in ASDs. This work was supported in part by a grant from Clarkson University (start-up to C.C.D.) and US Army Research Office (DURIP grant \#W911NF-11-1-0304 to C.C.D.).

\section{Author details}

'Biochemistry and Proteomics Group Department of Chemistry and Biomolecular Science, Clarkson University, 8 Clarkson Avenue, Potsdam, NY 13699-5810, USA. ${ }^{2}$ Department of Psychology, State University of New York at Plattsburgh, 101 Broad Street, Plattsburgh, NY 12901, USA. ${ }^{3}$ Department of Psychiatry, University of Rostock, Gehlsheimer Straße 20, D-18147, Rostock, Germany. ${ }^{4}$ College of Medicine, Swansea University, Singleton Park, Swansea SA2 8PP, UK

Received: 2 October 2012 Accepted: 13 November 2012 Published: 21 May 2013

\section{References}

1. DiCicco-Bloom E, Lord C, Zwaigenbaum L, Courchesne E, Dager SR, Schmitz C, Schultz RT, Crawley J, Young L: The developmental neurobiology of autism spectrum disorder. J Neurosci 2006, 26(26):6897-6906.

2. APA: Diagnostic and Statistical Manual of Mental Disorders. American Psychiatric Association: Fourth Edition, Text Revision. Arlington, VA; 2000.

3. Autism, Developmental Disabilities Monitoring Network Surveillance Year Principal I, Centers for Disease C, Prevention: Prevalence of autism spectrum disorders--Autism and Developmental Disabilities Monitoring Network, 14 sites, United States, 2008. Morb Mortal Wkly Rep Surveill Summ 2012, 61(3):1-19.

4. Dettmer K, Hanna D, Whetstone P, Hansen R, Hammock BD: Autism and urinary exogenous neuropeptides: development of an on-line SPE-HPLC -tandem mass spectrometry method to test the opioid excess theory. Anal Bioanal Chem 2007, 388(8):1643-1651.

5. Tanguay PE: Autism in DSM-5. Am J Psychiatry 2011, 168(11):1142-1144.

6. Matson JL, Kozlowski AM, Hattier MA, Horovitz M, Sipes M: DSM-IV vs DSM-5 diagnostic criteria for toddlers with Autism. Dev Neurorehabil 2012, 15(3):185-190.

7. Zappella M: Reversible autism and intellectual disability in children. Am J Med Genet C Semin Med Genet 2012, 160C(2):111-117.

8. Lovaas Ol: Behavioral treatment and normal educational and intellectual functioning in young autistic children. J Consult Clin Psychol 1987, 55(1):3-9.

9. McEachin JJ, Smith T, Lovaas Ol: Long-term outcome for children with autism who received early intensive behavioral treatment. AJMR 1993, 97(4):359-372. discussion 373-391.

10. Sallows GO, Graupner TD: Intensive behavioral treatment for children with autism: four-year outcome and predictors. AJMR 2005, 110(6):417-438.

11. Leskovec TJ, Rowles BM, Findling RL: Pharmacological treatment options for autism spectrum disorders in children and adolescents. Harv Rev Psychiatry 2008, 16(2):97-112.

12. Myers SM: The status of pharmacotherapy for autism spectrum disorders. Expert Opin Pharmacother 2007, 8(11):1579-1603.

13. Rogers SJ, Vismara LA: Evidence-based comprehensive treatments for early autism. J Clin Child Adolesc Psychol 2008, 37(1):8-38.

14. Hagerman R, Lauterborn J, Au J, Berry-Kravis E: Fragile $\mathrm{X}$ syndrome and targeted treatment trials. Results Probl Cell Differ 2012, 54:297-335.

15. Michel TM, Sheldrick AJ, Frentzel TG, Herpertz-Dahlmann B, Herpertz S, Habel U, Bruegmann E, Schneider K: Schneider F: [Evaluation of diagnostic and therapeutic services in German university hospitals for adults with autism spectrum disorder (ASD)]. Fortschr Neurol Psychiatr 2010, 78(7):402-413.

16. Simonoff E, Jones CR, Pickles A, Happe F, Baird G, Charman T: Severe mood problems in adolescents with autism spectrum disorder. J Child Psychol Psychiatry 2012.

17. Frustaci A, Neri M, Cesario A, Adams JB, Domenici E, Dalla Bernardina B, Bonassi S: Oxidative stress-related biomarkers in autism: Systematic review and meta-analyses. Free Radic Biol Med 2012, 52(10):2128-2141.

18. Conciatori M, Stodgell CJ, Hyman SL, O'Bara M, Militerni R, Bravaccio C, Trillo S, Montecchi F, Schneider C, Melmed R, et al: Association between the HOXA1 A218G polymorphism and increased head circumference in patients with autism. Biol Psychiatry 2004, 55(4):413-419.

19. Freitag CM, Staal W, Klauck SM, Duketis E, Waltes R: Genetics of autistic disorders: review and clinical implications. Eur Child Adolesc Psychiatry 2010, 19(3):169-178.

20. Hu WW, Nguyen A, Kim KS, Steinberg ME, Sarachana T, Scully MA, Soldin SJ, Luu T, Lee NH: Gene expression profiling of lymphoblasts from autistic 
and nonaffected sib pairs: altered pathways in neuronal development and steroid biosynthesis. PLoS One 2009, 4(6):e5775.

21. State MW, Levitt $P$ : The conundrums of understanding genetic risks for autism spectrum disorders. Nat Neurosci 2011, 14(12):1499-1506.

22. Bailey A, Le Couteur A, Gottesman I, Bolton P, Simonoff E, Yuzda E, Rutter M: Autism as a strongly genetic disorder: evidence from a British twin study. Psychol Med 1995, 25(1):63-77.

23. Le Couteur A, Bailey A, Goode S, Pickles A, Robertson S, Gottesman I, Rutter M: A broader phenotype of autism: the clinical spectrum in twins. J Child Psychol Psychiatry 1996, 37(7):785-801.

24. Betancur C: Etiological heterogeneity in autism spectrum disorders: more than 100 genetic and genomic disorders and still counting. Brain Res 2011, 1380:42-77.

25. Nickl-Jockschat T, Michel TM: Genetic and brain structure anomalies in autism spectrum disorders. Towards an understanding of the aetiopathogenesis? Nervenarzt 2011, 82(5):618-627.

26. Neale BM, Kou Y, Liu L, Ma'ayan A, Samocha KE, Sabo A, Lin CF, Stevens C, Wang LS, Makarov V, et al: Patterns and rates of exonic de novo mutations in autism spectrum disorders. Nature 2012, 485(7397):242-245.

27. Leblond CS, Heinrich J, Delorme R, Proepper C, Betancur C, Huguet G, Konyukh M, Chaste P, Ey E, Rastam M, et al: Genetic and functional analyses of SHANK2 mutations suggest a multiple hit model of autism spectrum disorders. PLoS Genet 2012, 8(2):e1002521.

28. Gurrieri F: Working up autism: The practical role of medical genetics. Am J Med Genet C Semin Med Genet 2012, 160C(2):104-110.

29. Lee TL, Raygada MJ, Rennert OM: Integrative gene network analysis provides novel regulatory relationships, genetic contributions and susceptible targets in autism spectrum disorders. Gene 2012, 496(2):88-96.

30. Nickl-Jockschat T, Michel TM: The role of neurotrophic factors in autism. Mol Psychiatry 2011, 16(5):478-490.

31. Theoharides TC, Kempuraj D, Redwood L: Autism: an emerging 'neuroimmune disorder' in search of therapy. Expert Opin Pharmacother 2009, 10(13):2127-2143.

32. Veenstra-VanderWeele J, Blakely RD: Networking in autism: leveraging genetic, biomarker and model system findings in the search for new treatments. Neuropsychopharmacol 2012, 37(1):196-212.

33. Woods AG, Sokolowska I, Taurines R, Gerlach M, Dudley E, Thome J, Darie CC: Potential biomarkers in psychiatry: focus on the cholesterol system. J Cell Mol Med 2012.

34. Dereu M, Roeyers H, Raymaekers R, Meirsschaut M, Warreyn P: How useful are screening instruments for toddlers to predict outcome at age 4 ? General development, language skills, and symptom severity in children with a false positive screen for autism spectrum disorder. Eur Child Adolesc Psychiatry 2012.

35. Junaid MA, Pullarkat RK: Proteomic approach for the elucidation of biological defects in autism. J Autism Dev Disord 2001, 31(6):557-560.

36. Woods AG, Sokolowska I, Yakubu R, Butkiewicz M, LaFleur M, Talbot C, Darie CC: Blue native page and mass spectrometry as an approach for the investigation of stable and transient protein-protein interactions Oxidative Stress: Diagnostics, Prevention, and Therapy. edn. Edited by Andreescu S, Hepel M. Washington, D.C.: American Chemical Society; 2011.

37. Anderson L, Seilhamer J: A comparison of selected mRNA and protein abundances in human liver. Electrophoresis 1997, 18(3-4):533-537.

38. Taurines R, Dudley E, Grassl J, Warnke A, Gerlach M, Coogan AN, Thome J: Proteomic research in psychiatry. J Psychopharmacol 2011, 25(2):151-196.

39. Kern JK, Grannemann BD, Trivedi MH, Adams JB: Sulfhydryl-reactive metals in autism. J Toxicol Environ Health A 2007, 70(8):715-721.

40. Thomas RH, Foley KA, Mepham JR, Tichenoff LJ, Possmayer F, MacFabe DF: Altered brain phospholipid and acylcarnitine profiles in propionic acid infused rodents: further development of a potential model of autism spectrum disorders. J Neurochem 2010, 113(2):515-529.

41. Klemmer P, Meredith RM, Holmgren CD, Klychnikov Ol, Stahl-Zeng J, Loos $M$, van der Schors RC, Wortel J, de Wit H, Spijker S, et al: Proteomics, ultrastructure, and physiology of hippocampal synapses in a fragile $X$ syndrome mouse model reveal presynaptic phenotype. J Biol Chem 2011, 286(29):25495-25504.

42. Lista S, Faltraco F, Hampel H: Blood and plasma-based proteomic biomarker research in Alzheimer's disease. Prog Neurobiol 2012.

43. Amado FM, Ferreira RP, Vitorino R: One decade of salivary proteomics: Current approaches and outstanding challenges. Clin Biochem 2012.
44. Tambor V, Fucikova A, Lenco J, Kacerovsky M, Rehacek V, Stulik J, Pudil R: Application of proteomics in biomarker discovery: a primer for the clinician. Physiol Res 2010, 59(4):471-497.

45. Lovestone S, Guntert A, Hye A, Lynham S, Thambisetty M, Ward M: Proteomics of Alzheimer's disease: understanding mechanisms and seeking biomarkers. Expert Rev Proteomics 2007, 4(2):227-238.

46. Darie CC, Biniossek ML, Gawinowicz MA, Milgrom Y, Thumfart JO, Jovine L, Litscher ES, Wassarman PM: Mass spectrometric evidence that proteolytic processing of rainbow trout egg vitelline envelope proteins takes place on the egg. J Biol Chem 2005, 280(45):37585-37598.

47. Darie CC, Biniossek ML, Winter V, Mutschler B, Haehnel W: Isolation and structural characterization of the Ndh complex from mesophyll and bundle sheath chloroplasts of Zea mays. FEBS J 2005, 272(11):2705-2716.

48. Darie CC, Deinhardt K, Zhang G, Cardasis HS, Chao MV, Neubert TA: Identifying transient protein-protein interactions in EphB2 signaling by blue native PAGE and mass spectrometry. Proteomics 2011, 11(23):4514-4528.

49. Darie CC, Janssen WG, Litscher ES, Wassarman PM: Purified trout egg vitelline envelope proteins VEbeta and VEgamma polymerize into homomeric fibrils from dimers in vitro. Biochim Biophys Acta 2008 1784(2):385-392

50. Jovine L, Darie CC, Litscher ES, Wassarman PM: Zona pellucida domain proteins. Annu Rev Biochem 2005, 74:83-114.

51. Litscher ES, Janssen WG, Darie CC, Wassarman PM: Purified mouse egg zona pellucida glycoproteins polymerize into homomeric fibrils under non-denaturing conditions. J Cell Physiol 2008, 214(1):153-157.

52. Ngounou Wetie AG, Sokolowska I, Woods AG, Roy U, Loo JA, Darie CC: Investigation of stable and transient protein-protein interactions: past, present and future. Proteomics 2012.

53. Ngounou Wetie AG, Sokolowska I, Woods AG, Wormwood KL, Dao S, Patel S: Clarkson BD. Darie CC: Automated Mass Spectrometry-Based Functional Assay for the Routine Analysis of the Secretome. Journal of laboratory automation; 2012.

54. Sokolowska I, Dorobantu C, Woods AG, Macovei A, Branza-Nichita N Darie CC: Proteomic analysis of plasma membranes isolated from undifferentiated and differentiated HepaRG cells. Proteome Sci 2012, 10(1):47.

55. Sokolowska I, Gawinowicz MA, Wetie AG, Darie CC: Disulfide proteomics for identification of extracellular or secreted proteins. Electrophoresis 2012 33(16):2527-2536.

56. Sokolowska I, Ngounou Wetie AG: Woods AG. Darie CC: Automatic Determination of Disulfide Bridges in Proteins. Journal of laboratory automation; 2012.

57. Sokolowska I, Woods AG, Gawinowicz MA, Roy U, Darie CC: Characterization of Tumor Differentiation Factor (TDF) and its receptor (TDF-R). Cell Mol Life Sci 2012.

58. Spellman DS, Deinhardt K, Darie CC, Chao MV, Neubert TA: Stable isotopic labeling by amino acids in cultured primary neurons: application to brain-derived neurotrophic factor-dependent phosphotyrosineassociated signaling. Mol Cell Proteomics 2008, 7(6):1067-1076.

59. Woods AG, Sokolowska I, Darie CC: Identification of consistent alkylation of cysteine-less peptides in a proteomics experiment. Biochem Biophys Res Commun 2012, 419(2):305-308.

60. Roy U, Sokolowska I, Woods AG, Darie CC: Structural Investigation of Tumor Differentiation Factor (TDF). Biotechnol Appl Biochem 2012.

61. Armirotti A, Damonte G: Achievements and perspectives of top-down proteomics. Proteomics 2010, 10(20):3566-3576.

62. Sokolowska I, Woods AG, Wagner J, Dorler J, Wormwood K, Thome J, Darie CC: Mass spectrometry for proteomics-based investigation of oxidative stress and heat shock proteins Oxidative Stress: Diagnostics, Prevention, and Therapy. edn. Edited by Andreescu S, Hepel M. Washington, D.C.: American Chemical Society; 2011.

63. Lam KS, Aman MG, Arnold LE: Neurochemical correlates of autistic disorder: a review of the literature. Res Dev Disabil 2006, 27(3):254-289.

64. Cass H, Gringras P, March J, McKendrick I, O'Hare AE, Owen L, Pollin C: Absence of urinary opioid peptides in children with autism. Arch Dis Child 2008, 93(9):745-750.

65. Hunter LC, O'Hare A, Herron WJ, Fisher LA, Jones GE: Opioid peptides and dipeptidyl peptidase in autism. Dev Med Child Neurol 2003, 45(2):121-128.

66. Albizzati A, More L, Di Candia D, Saccani M, Lenti C: Normal concentrations of heavy metals in autistic spectrum disorders. Minerva Pediatr 2012, 64(1):27-31. 
67. Owens SE, Summar ML, Ryckman KK, Haines JL, Reiss S, Summar SR, Aschner M: Lack of association between autism and four heavy metal regulatory genes. Neurotoxicology 2011, 32(6):769-775

68. Montaser A, McLean JA, Liu H, Mermet J-M: An introduction to ICP spectrometries for elemental analysis Plasma Mass Spectrometry. edn. Edited by Montaser A. Hoboken, NJ: John Wiley \& Sons; 1998.

69. Soden SE, Lowry JA, Garrison CB, Wasserman GS: 24-hour provoked urine excretion test for heavy metals in children with autism and typically developing controls, a pilot study. Clin Toxicol 2007, 45(5):476-481.

70. Emanuele E, Colombo R, Martinelli V, Brondino N, Marini M, Boso M, Barale F, Politi P: Elevated urine levels of bufotenine in patients with autistic spectrum disorders and schizophrenia. Neuro Endocrinol Lett 2010, 31(1):117-121.

71. McBride MC: Bufotenine: toward an understanding of possible psychoactive mechanisms. J Psychoactive Drugs 2000, 32(3):321-331.

72. Takeda N: Serotonin-degradative pathways in the toad (Bufo bufo japonicus) brain: clues to the pharmacological analysis of human psychiatric disorders. Comp Biochem Physiol Pharmacol Toxicol Endocrinol 1994, 107(2):275-281.

73. Hites RA: Gas chromatography mass spectrometry Instrumental Techniques for Analytical Chemistry. edn. Edited by Settle F. Upper Saddle River, NJ: Prentice-Hall; 1997

74. Kałuzna-Czaplinska J, Michalska M, Rynkowski J: Determination of tryptophan in urine of autistic and healthy children by gas chromatography/mass spectrometry. Med Sci Monit 2010, 16(10):CR488-492.

75. Pedersen OS, Liu Y, Reichelt KL: Serotonin uptake stimulating peptide found in plasma of normal individuals and in some autistic urines. J Pept Res, 53(6):641-646.

76. Yao Y, Walsh WJ, McGinnis WR, Pratico D: Altered vascular phenotype in autism: correlation with oxidative stress. Arch Neuro/ 2006, 63(8):1161-1164.

77. Taurines R, Dudley E, Conner AC, Grassl J, Jans T, Guderian F, Mehler-Wex C, Warnke A, Gerlach M, Thome J: Serum protein profiling and proteomics in autistic spectrum disorder using magnetic bead-assisted mass spectrometry. Eur Arch Psychiatry Clin Neurosci 2010, 260(3):249-255.

78. Corbett BA, Kantor AB, Schulman H, Walker WL, Lit L, Ashwood P, Rocke DM, Sharp FR: A proteomic study of serum from children with autism showing differential expression of apolipoproteins and complement proteins. Mol Psychiatry 2007, 12(3):292-306

79. Aneja A, Tierney E: Autism: the role of cholesterol in treatment. Int Rev Psychiatry 2008, 20(2):165-170.

80. Tierney E, Bukelis I, Thompson RE, Ahmed K, Aneja A, Kratz L, Kelley RI: Abnormalities of cholesterol metabolism in autism spectrum disorders. Am J Med Genet 2006, 141B(6):666-668.

81. Hertz-Picciotto I, Croen LA, Hansen R, Jones CR, van de Water J, Pessah IN: The CHARGE study: an epidemiologic investigation of genetic and environmental factors contributing to autism. Environ Health Perspect 2006, 114(7):1119-1125.

82. Hertz-Picciotto I, Green PG, Delwiche L, Hansen R, Walker C, Pessah IN: Blood mercury concentrations in CHARGE Study children with and without autism. Environ Health Perspect 2010, 118(1):161-166.

83. Hertz-Picciotto I, Bergman A, Fangstrom B, Rose M, Krakowiak P, Pessah I, Hansen R, Bennett DH: Polybrominated diphenyl ethers in relation to autism and developmental delay: a case-control study. Environ HealthGlob 2011, 10(1):1.

84. Russo AJ, Devito R: Analysis of Copper and Zinc Plasma Concentration and the Efficacy of Zinc Therapy in Individuals with Asperger's Syndrome, Pervasive Developmental Disorder Not Otherwise Specified (PDD-NOS) and Autism. Biomarker insights 2011, 6:127-133.

85. Godler DE, Slater HR, Bui QM, Ono M, Gehling F, Francis D, Amor DJ, Hopper JL, Hagerman R, Loesch DZ: FMR1 intron 1 methylation predicts FMRP expression in blood of female carriers of expanded FMR1 alleles. J Mol Diagn 2011, 13(5):528-536.

86. Godler DE, Slater HR, Bui QM, Storey E, Ono MY, Gehling F, Inaba Y, Francis D, Hopper $J$, Kinsella G, et al: Fragile X mental retardation 1 (FMR1) intron 1 methylation in blood predicts verbal cognitive impairment in female carriers of expanded FMR1 alleles: evidence from a pilot study. Clin Chem 2012, 58(3):590-598.

87. Hu S, Li Y, Wang J, Xie Y, Tjon K, Wolinsky L, Loo RR, Loo JA, Wong DT: Human saliva proteome and transcriptome. J Dent Res 2006, 85:1129-1133.

88. Wiesen MH, Farowski F, Feldkotter M, Hoppe B, Muller C: Liquid chromatography-tandem mass spectrometry method for the quantification of mycophenolic acid and its phenolic glucuronide in saliva and plasma using a standardized saliva collection device. J Chromatogr A 2012, 1241:52-59.

89. Border MB, Schwartz S, Carlson J, Dibble CF, Kohltfarber H, Offenbacher S, Buse $\mathrm{JB}$, Bencharit $\mathrm{S}$ : Exploring salivary proteomes in edentulous patients with type 2 diabetes. Mol Biosyst 2012, 8(4):1304-1310

90. Shi M, Sui YT, Peskind ER, Li G, Hwang H, Devic I, Ginghina C, Edgar JS, Pan C, Goodlett DR, et al: Salivary tau species are potential biomarkers of Alzheimer's disease. J Alzheimers Dis 2011, 27(2):299-305.

91. Soukup M, Biesiada I, Henderson A, Idowu B, Rodeback D, Ridpath L, Bridges EG, Nazar AM, Bridges KG: Salivary uric acid as a noninvasive biomarker of metabolic syndrome. Diab Metab Synd 2012, 4(1):14.

92. Castagnola M, Messana I, Inzitari R, Fanali C, Cabras T, Morelli A, Pecoraro AM, Neri G, Torrioli MG, Gurrieri F: Hypo-phosphorylation of salivary peptidome as a clue to the molecular pathogenesis of autism spectrum disorders. J Proteome Res 2008, 7(12):5327-5332.

93. Sokolowska I, Woods AG, Gawinowicz MA, Roy U, Darie CC: Identification of a potential tumor differentiation factor receptor candidate in prostate cancer cells. FEBS J 2012, 279(14):2579-2594.

94. Sokolowska I, Woods AG, Gawinowicz MA, Roy U, Darie CC: Identification of potential tumor differentiation factor (TDF) receptor from steroidresponsive and steroid-resistant breast cancer cells. J Biol Chem 2012, 287(3):1719-1733.

95. Darie CC, Shetty V, Spellman DS, Zhang G, Xu C, Cardasis HL, Blais S, Fenyo D, Neubert T: A.: Blue Native PAGE and mass spectrometry analysis of the ephrin stimulation- dependent protein-protein interactions in NG108-EphB2 cells. Düsseldorf, Germany: Springer; 2008.

96. Darie CC, Biniossek ML, Jovine L, Litscher ES, Wassarman PM: Structural characterization of fish egg vitelline envelope proteins by mass spectrometry. Biochemistry 2004, 43(23):7459-7478.

97. Darie CC, Litscher ES, Wassarman PM: Structure, processing, and polymerization of rainbow trout egg vitelline envelope proteins. Düsseldorf, Germany: Springer; 2008.

98. Godler DE, Tassone F, Loesch DZ, Taylor AK, Gehling F, Hagerman RJ, Burgess T, Ganesamoorthy D, Hennerich D, Gordon L, et al: Methylation of novel markers of fragile $X$ alleles is inversely correlated with FMRP expression and FMR1 activation ratio. Hum Mol Genet 2010, 19(8):1618-1632.

doi:10.1186/2049-9256-1-6

Cite this article as: Woods et al:: Mass spectrometry as a tool for studying autism spectrum disorder. Journal of Molecular Psychiatry 2013 1:6.

\section{Submit your next manuscript to BioMed Central and take full advantage of:}

- Convenient online submission

- Thorough peer review

- No space constraints or color figure charges

- Immediate publication on acceptance

- Inclusion in PubMed, CAS, Scopus and Google Scholar

- Research which is freely available for redistribution 